\title{
Bidirectional Operation of the Single-Phase Neutral-Point-Clamped Quasi-Z-Source Inverter
}

\author{
O. Husev ${ }^{1,3}$, J. Zakis ${ }^{2}$, D. Vinnikov ${ }^{1,2}$, O. Savenko ${ }^{3}$ \\ ${ }^{1}$ Department of Electrical Engineering, Tallinn University of Technology, Tallinn, Estonia \\ ${ }^{2}$ Institute of Industrial Electronics and Electrical Engineering, Riga Technical University, Riga, Latvia \\ ${ }^{3}$ Department of Biomedical Radioelectronic Apparatus and Systems, Chernihiv State Technological University, \\ Chernihiv, Ukraine \\ E-mail: oleksandr.husev@iieee.org
}

\begin{abstract}
This paper shows the bidirectional operation possibility of the single phase three-level neutral-point-clamped quasi-Z-source grid connected inverter. The simple traditional control system for three-level grid connected rectifier was implemented. Simulation results confirmed bidirectional operation capability of the discussed topology.
\end{abstract}

Keywords-FPGA; control system; three-level inverter; neutral point clamped inverter; quasi-Z-source inverter

\section{INTRODUCTION}

A new modification of the quasi-Z-source (qZS) inverter - a three-level neutral-point-clamped (3L NPC) quasi-Z-source inverter has been proposed and discussed in several papers [1][4]. This topology was presented as novel solution for photovoltaic (PV) application with wide input voltage regulation range, continuous input current mode, short circuit immunity and high switching frequency.

Fig. 1 shows generalized case study system. It contains PV panel string, quasi-Z-source (qZS) network, three-level NPC inverter with grid side inductor connected to the grid. Such topology provides the energy transfer from PV panels to the grid. Thanks to shoot through states this is a single stage buckboost solution that is capable to perform maximum power point tracking (MPPT) and inversion with no need for an extra DC/DC converter.

In addition, special functions, such as power factor corrections or active filtering, can be implemented.

At the same time there is a modern trend in similar solutions to provide bidirectional performance of PV inverters by means of heater element [5]-[10]. It is required to melt snow in the frosty conditions [11], [12]. It can be accomplished by providing a solar collector system having at least one evacuated tube solar collector, a conductor arranged on the solar collector, a power source for sending electricity through the conductor, and an indicator connected to the conductor to indicate when electricity is flowing through the conductor. Such function can be easily implemented by means of bidirectional converter. In order to provide bidirectional operation the qZS diodes must be replaced by the two quadrant switches.

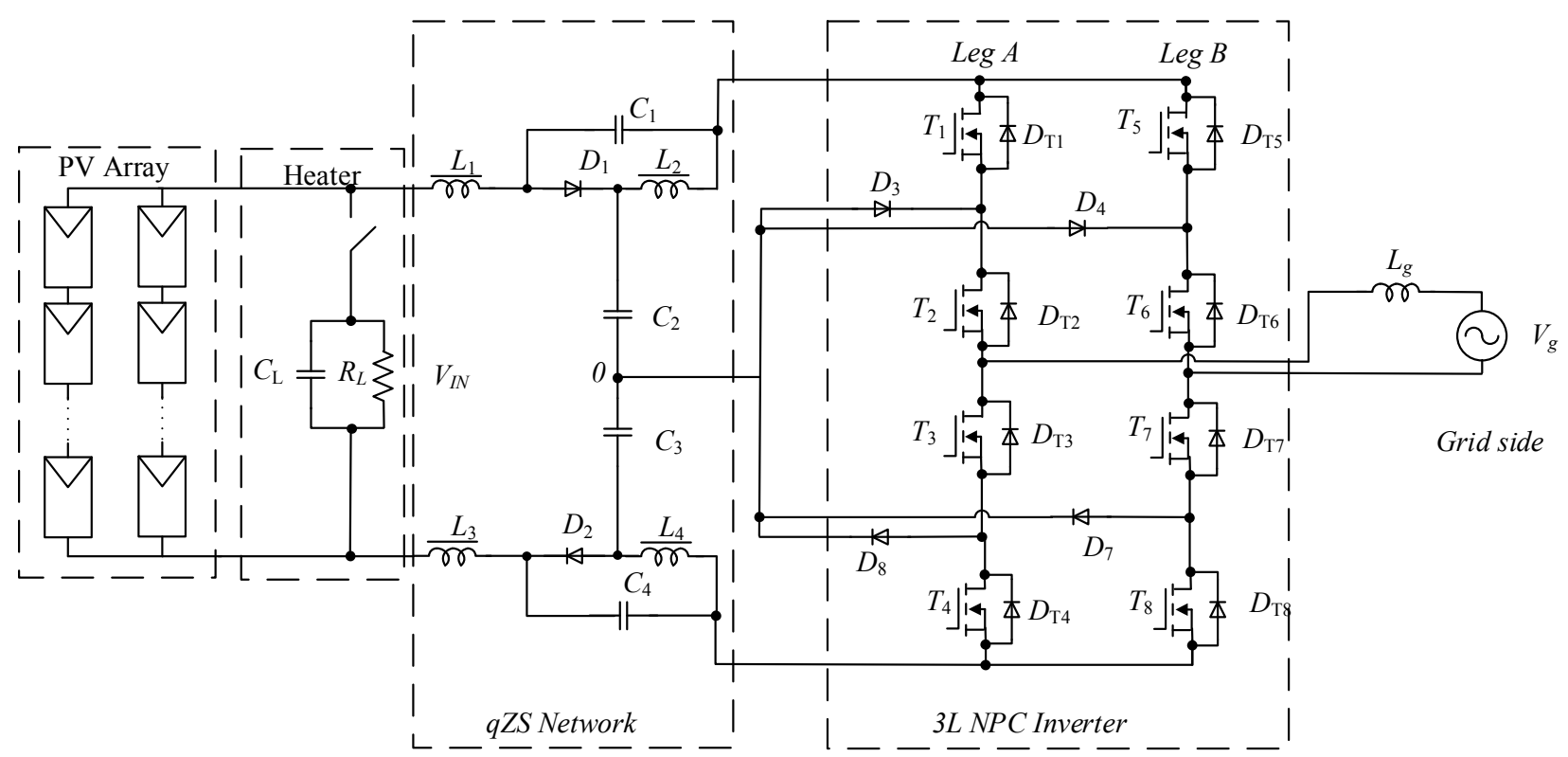

Fig. 1. General circuit diagram of discussed system. 
The conductor is preferably formed from a material that heats up quickly when electrical current is applied to it. In Fig. 1 this conductor is represented as a heater. The electricity flow heats the conductor and melts the snow on the collector.

Fig. 2 shows modified topology with qZS diodes replacement.

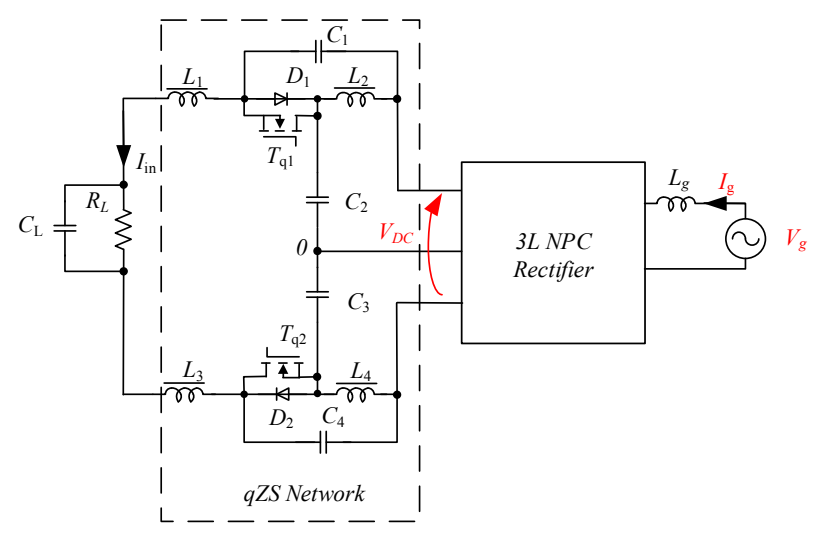

Fig. 2. Single phase $3 \mathrm{~L}$ qZS NPC inverter with replaced qZS diodes.

In this case transistors $T q_{1}$ and $T q_{2}$ control the power flow direction. If they are switched off the scheme operates as a PV inverter, if they are switched on the scheme operates like a rectifier. In the second case the PV string is represented like passive load with parallel capacitor. DC-link voltage $V_{D C}$, grid current $I_{g}$ and voltage $V_{g}$ are the parameters under control. Input current $I_{i n}$ is a current in the heater.

\section{DESCRIPTION OF CONTROL SYSTEM}

Table I shows the parameters of the discussed topology as well as control system parameters used in simulation.

\section{TABLE I. SYSTEM PARAMETERS}

\begin{tabular}{|l|c|}
\hline \multicolumn{1}{|c|}{ Parameter } & Value \\
\hline Input DC voltage $V_{I N}$ & $220-440 \mathrm{~V}$ \\
\hline Nominal output AC voltage $V_{\text {OUT }}$ & $230 \mathrm{~V}$ \\
\hline Capacitance value of the capacitors $C_{l}, C_{4}$ & $4000 \mathrm{uF}$ \\
\hline Capacitance value of the capacitors $C_{2}, C_{3}$ & $1000 \mathrm{uF}$ \\
\hline Inductance value of the inductors $L_{1} \ldots L_{4}$ & $145 \mathrm{uH}$ \\
\hline Inductance of the grid inductor $L_{g}$ & $2.2 \mathrm{mH}$ \\
\hline Switching frequency & $100 \mathrm{kHz}$ \\
\hline PV panels & LDK $185 \mathrm{D}(180 \mathrm{~W}$, \\
\hline Number of panels in series & $74 \mathrm{~V})$ \\
\hline Time constant of PI controller & $10^{-9}$ \\
\hline Gain of the PI controller & $10^{3}$ \\
\hline
\end{tabular}

Whereas there is no difference between classical three-level rectifier and our case from control point of view, the scetch of the proposed control system is depicted in Fig. 3. There are many studies devoted to the existed possible solutions [13] - [16]. Since the control system is not an object of the research we have chosen one of the simplest and easy to implement control approaches.

It can be seen that the basic idea is in the DC-link voltage control $V_{D C}$. The error between $V_{D C}$ and reference value enters the PI regulator the output signal of which defines the amplitude of the grid consuming current.

\section{Control System}

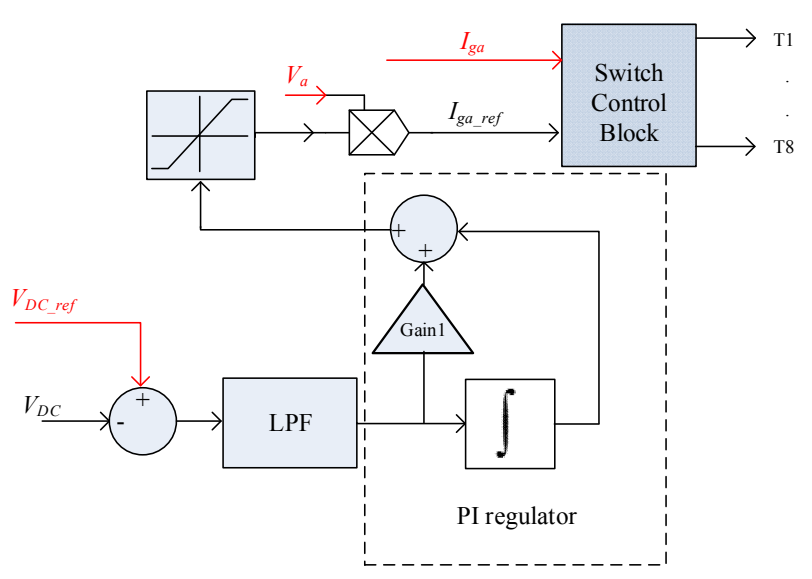

Fig. 3. The sketch of the proposed control system.

The measured grid voltage $V_{g}$ is used for reference current waveform generation by means of multiplication $V_{g}$ value by PI regulator output signal.

Switch control block implements traditional PWM technique, that is based on the comparison between grid and reference current [16].

\section{Simulation RESUlts}

The results of the simulation study are described in this section. The main goal of simulation is to confirm bidirectional operation capability of the discussed topology.

The PSIM model was used for simulation. Parameters are in correspondence with Table I. As it was mentioned above the PV panels are represented by means of load resistor with paralel capacitor. The PI regulator parameters were tuned in order to avoid stability problem.

Fig. 4 shows transient process of the power flow from grid to PV panels. Preliminary the output resistor value was $120 \mathrm{Ohms}$ that corresponded to $1.3 \mathrm{~kW}$. We can see that DC-link value achieves reference value at the moment of time $0.4 \mathrm{~s}$. It should be emphasised that there is no any significant voltage or current stress during transient response. It is explained by presence of the grid side inductor along with the passive qZS network. At the moment of time $0.4 \mathrm{~s}$ the load goes down to the half of initial value. It is evident that minor overvoltage follows transient response. Finally we can claim that DC-link voltage tends to the reference value. 

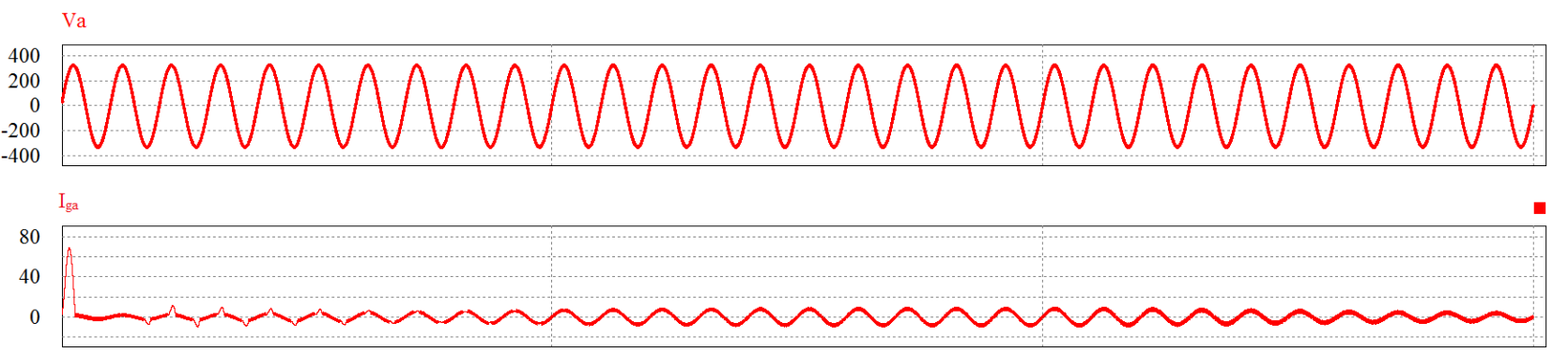

$\begin{array}{lll}\mathrm{V}_{\mathrm{DC}} & \mathrm{V}_{\mathrm{C} 1} & \mathrm{~V}_{\mathrm{C} 2}\end{array}$

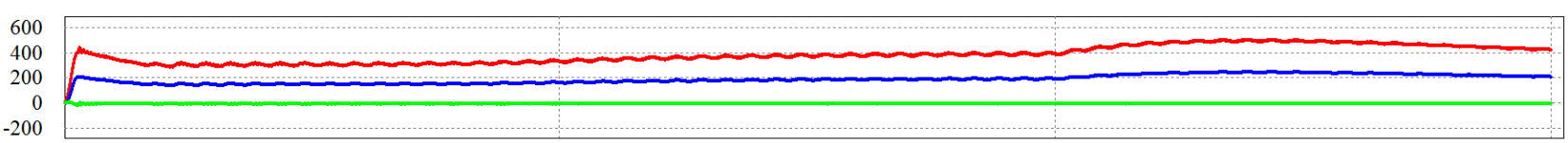

Iin

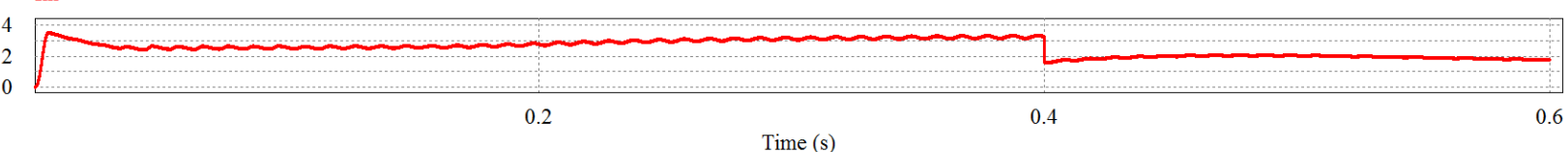

Fig. 4. Transient response of the $3 \mathrm{~L}$ qZS NPC as rectifier.

The qZS network was preliminary designed in order to provide continuous conduction mode (CCM) converter behavior in full operation range [2]. The main conclusion from the above presented diagrams is that despite of the single phase low frequency power fluctuation the DC-link voltage has acceptable minor ripple in the case of inverse power flow.

Fig. 5 demonstrates the diagrams in steady state mode. All current and voltage waveforms are in full agreement with theoretically expected results.

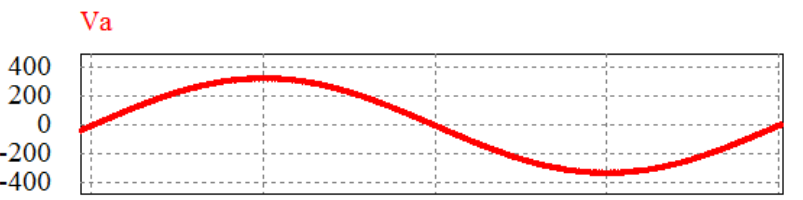$$
\text { Iga }
$$
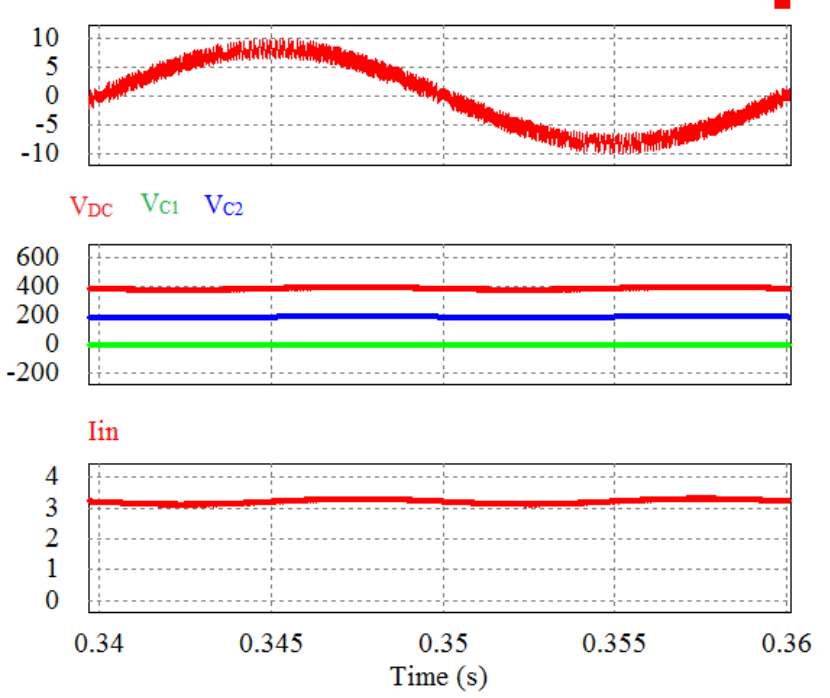

Fig. 5. The simulation waveforms in the steady state mode.
Analyzing the obtained diagrams, we can claim that when demanded power on the DC-link side goes down the low frequency ripple significantly decreases. Also it should be noted that power range used in simulation was used in order to demonstrate the bidirectional capability. In fact the demanded power for snow melting is much less.

\section{CONCLUSIONS}

This paper considers the bidirectional operation of the single phase 3L NPC qZSI. In order to realize this function the two quadrant switches were implemented instead of qZS diodes. The simple traditional control system of 3-level grid connected rectifier was realised. Simulation results confirmed bidirectional operation capability of the discussed topology.

The qZS network has low pass filter features in such application. As a result, there are no current or voltage stresses during transient response. Also it mitigates low frequency oscillation in the output PV heater current.

At the same time it should be noted that bidirectional operation requires transistors with fast body diodes that operate like qZS diodes in direct power convertion mode. Since the transistor itself must not be fast switching the IGBT transistor with fast body diode can be used. There is another possible solution based on fast Shottky body diode of the SiC MOSFETs that are already available on the market. Such semiconductor switches can realize bidirectional operation with negligable losses in the both energy flux directions.

\section{ACKNOWLEDGMENT}

This research has been supported by the Estonian Ministry of Education and Research (projects 
SF0140016s11 and B23), by Estonian Research Council (Grant G8538), MOBILITAS Postdoctoral Research Grant (MJD391). Latvian partner research work has been supported by Latvian Council of Science (Grant 673/2014).

\section{REFERENCES}

[1] O. Husev, S. Stepenko, C.Roncero-Clemente, E. Romero-Cadaval, D. Vinnikov, "Single-Phase Three-Level Quasi-Z-Source Inverter with a New Boost Modulation Technique," Proceedings of IECON 2012 - 38th Annual Conference on IEEE Industrial Electronics Society, pp. 5856-5861, Montreal, Canada, October 25-28, 2012.

[2] O. Husev, C. Roncero-Clemente, S. Stepenko, D. Vinnikov, E. Romero-Cadaval, "CCM Operation Analysis of the Single-Phase Three-Level Quasi-Z-Source Inverter," In: Proceedings of 15th International Power Electronics and Motion Control Conference and Exposition, EPE-PEMC 2012, September 4-6, 2012.

[3] S. Stepenko, O. Husev., D. Vinnikov, S. Ivanets, "FPGA Control of the Neutral Point Clamped Quasi-Z-Source Inverter," Proceedings of the 13th Biennial Baltic Electronics Conference (Tallinn, Estonia, 3-5 October 2012). - Tallinn: TUT, 2012. - pp 263-266.

[4] C. Roncero-Clemente, O. Husev, V. Minambres-Marcos, E. Romero-Cadaval, S. Stepenko, D. Vinnikov, "Tracking of MPP for three-level neutral-point-clamped qZ-source off-grid inverter in solar applications," Journal of Microelectronics, Electronic Components and Materials Vol. 43, No. 4 (2013), pp. $212-221$

[5] J. Zakis, D. Vinnikov, I. Roasto, and L. Ribickis, "Quasi-Z-Source Inverter Based Bi-Directional DC/DC Converter: Analysis of Experimental Results", the 7th International Conference-Workshop Compatibility and Power Electronics, CPE, pp. 394-399, June 2011.

[6] H. Xu, F. Z. Peng, L. Chen and X. Wen "Analysis and design of bi-directional Z-source inverter for electrical vehicles", Proc. IEEE Appl. Power Electron. Conf. 2008, pp.1252 -1257
[7] S. Yang, F.Z. Peng, Q. Lei, R. Inoshita, Z. Qian, "Current-fed quasi-Z-source inverter with voltage buckboost and regeneration capability", Energy Conversion Congress and Exposition, IEEE, pp.3675-3682, 20-24 Sept. 2009.

[8] D. Sun, B. Ge, "Power flow control for quasi-Z source inverter with battery based PV power generation system", IEEE Energy Conversion Congress and Exposition: Energy Conversion Innovation for a Clean Energy Future, ECCE 2011, Proceedings, pp. 1051.

[9] K.N. Hasan, M.E. Haque, M. Negnevitsky, K.M. Muttaqi, "Control of energy storage interface with a bidirectional converter for photovoltaic systems", 2008 Australasian Universities Power Engineering Conference, AUPEC 2008

[10] O. Ellabban, H. Abu-Rub, J. Rodriguez, "Predictive torque control of an induction motor fed by a bidirectional quasi Z-source inverter". Proceedings of IECON 2013 - 39th Annual Conference on IEEE Industrial Electronics Society, pp. 5854-5859, Vienna, Austria, November 10-13, 2013.

[11] Brendan T. NICKEL "Snow melt system for solar collectors". Publication number US20130255665 A1, US patent $\mathrm{Nr}$ : 13/834,386, Mar 15, 2013

[12] Nobuyoshi Takehara; Naoki Manabe "Photovoltaic Power Generating System" US patent Nr: 6,093,885, Jul. 25, 2000.

[13] M. Liserre, A. Aquila and F. Blaabjerg, "An overview of threephase voltage source active rectifiers interfacing the utility", Proc. Bologna Power Tech Conf., 2003, vol. 3, pp. 1 -7.

[14] J. M. Kwon, B. H. Kwon and K. H. Nam, "Three-phase photovoltaic system with three-level boosting MPPT control", IEEE Trans. Power Electron., 2008, vol. 23, no. 5, pp.2319 2327.

[15] M.T. Zhang, Y. Jiang, F.C. Lee and M.M. Jovanovic, "Singlephase three-level boost power factor correction converter", Proc. IEEE APEC 1995, pp.434 -439.

[16] L. Dalessandro, S.D. Round, J.W Kolar, "Three-phase photovoltaic system with three-level boosting MPPT control", IEEE Trans. Power Electron., 2008, vol. 23, no. 5, pp.2477 -2488. 